\title{
Overview of FBO Licensing in the India and New Dietary Ingredient Notification in the US
}

\author{
Nandhini B ${ }^{1}$, MP Venkatesh ${ }^{2, \star}$, TM Pramod Kumar ${ }^{3}$ \\ ${ }^{1}$ Pharmaceutical Regulatory Affairs, JSS College of Pharmacy, JSS Academy of Higher Education and Research, Sri \\ Shivarathreeshwara Nagar, Mysuru, Karnataka, INDIA. \\ ${ }^{2}$ Department of Pharmaceutics, JSS College of Pharmacy, JSS Academy of Higher Education and Research, Sri Shivarathreeshwara \\ Nagar, Mysuru, Karnataka, INDIA. \\ ${ }^{3}$ JSS College of Pharmacy, JSS Academy of Higher Education and Research. Sri Shivarathreeshwara Nagar, Mysuru, Karnataka, \\ INDIA.
}

\begin{abstract}
The nutraceuticals in India are termed as "Foods for Special Dietary Uses" Food Safety and Standards Authority describes "Nutraceuticals provide a physiological benefit and help to maintain good health." FSSAI was recognized in India under the 2006 Food Safety and Standards Act, combines several acts and guidelines that existed in various ministries and departments to deal with food related substances. In US regulation, dietary supplements define "dietary supplement in part as product taken by mouth that contain a dietary ingredient. Dietary ingredients include nutrients, minerals and vitamins amino acids and herbs or botanicals and many other ingredients that can be used to enhance the diet. Demand for nutraceuticals is growing day by day, it has been noted that around $60-70 \%$ of dietary supplements marketed in India are false, counterfeit, unsecured and unauthorized. It is a problem that has not gone unnoticed by both the regulator and the industry. To take advantage of this demand, many new companies have begun manufacturing nutraceuticals. FSSAI has defined regulatory guidelines for approval of nutraceuticals in the Indian market. The aim of this article to have a closer look at nutraceuticals and their Food Business Operator (FBO) licensing, registration procedure and FSSAI key criteria for manufacturing nutraceuticals in India compared to US dietary supplement, submission and approval of NDI notification for New Dietary Ingredient. The nutraceutical industry has now developed into a growing organization fuelled by intense efforts to identify nutraceutical product characteristics and prospective applications, combined with customer demand and requirements.
\end{abstract}

Key words: FSSAI, Nutraceuticals, Dietary Supplements, Food Business Operator, DSHEA.

\section{INTRODUCTION}

Nutraceuticals, dietary supplements and functional food are often words which overlap. Over the years the rules and regulations in this product area have provided for these products with distinct meanings and regulations, keeping safety considerations in mind. Such requirements have grown further as the number of goods put on the market is growing. Food science research provides groundwork for the creation of these products. These goods have special claims for health benefits, or attempts to cure other illnesses or conditions several times. Regulations for these products vary from country to country and several products have been introduced on the market. A clear understanding of the nutraceuticals in a regulatory environment would reduce the uncertainty in setting the nutraceuticals policy. However, the regulatory status of nutraceuticals is different in the current scenario depending on the regulatory structure in the region.

This work provides a short overview of the Nutraceuticals Regulation developed under the U.S. Food and Drug Administration in
Submission Date: 15-07-2020; Revision Date: 09-10-2020; Accepted Date: 09-02-2021

DOI: 10.5530/ijper.55.2.71 Correspondence: Dr. MP Venkatesh Assistant Professor, Pharmaceutical Regulatory Affairs Group, Department of Pharmaceutics, JSS College of Pharmacy, JSS Academy of Higher Education and Research, Sri Shivarathreeshwara Nagar, Mysuru-570015, Karnataka, INDIA.

Phone no: +919886506306 Email id: venkateshmpv@ jssuni.edu.in

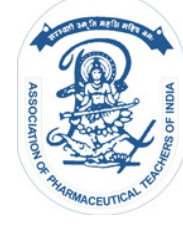

www.ijper.org 
the U.S. and the Food Safety Regulatory Authority of India (FSSAI) and its Food Business Operator (FBO) license and the registration process and the FSSAI Main Manufacturing Nutraceuticals Specifications in India compared to the U.S. Food Supplement and New Dietary Ingredient (NDI) application and approval.

\section{DISCUSSION}

\section{India ${ }^{1}$}

The FSSAI is authorizing authority that grants permission for the registering of food products and food commercial in the country to market the goods. This also encourages the general knowledge about the country's food health requirements. The Food Safety Regulations and Standards Act was formed in 2006 to create a legislative body regulating the production, storage, supply, selling and import of food and food products within the country. The FSS Act 2006, Rules and Regulations 2011 group nutraceutical under umbrella of the foods. The Food Safety and Quality Authority has released regulations about food business licensing and registration, processing, packaging and labelling, food product quality, etc. The FSSA has 12 sections with 101 sections and two timetables. The FSSAI combines the influential requirements of the Food Adulteration Act 1954 prevention through the aim of providing a common point of reference for all food health and quality matters.

The following are the essential aspects of the nutraceutical and dietary supplements in India:

(i) A product classified as 'Food for the Dietary Use or the Nutritional Food, Nutraceuticals, Health Supplements, the Related Foods' which are not intended for the traditional use and where these items may be manufactured in the form of dosage types and not parenterally intended for oral use.;

(ii) These Substances that are not included drugs in the Ayurveda, Siddha and in Unani Drugs

(iii) It should not claim to cure or relieve specific illness, illness or disorder (except for those statements relating to health benefits or marketing claims).) as acceptable under FSSA regulations. Figure 1 depicts Indian nutraceutical Market.

All the Food Business Operators must be licensed under India's FSSAI. The process and criteria for licensing and registration are governed by the Licensing and Registration of Food Business Regulations, 2011. The Main Indian Food categories are represented in Table 1 and Figure 2 represents the categories of FSSAI registration.

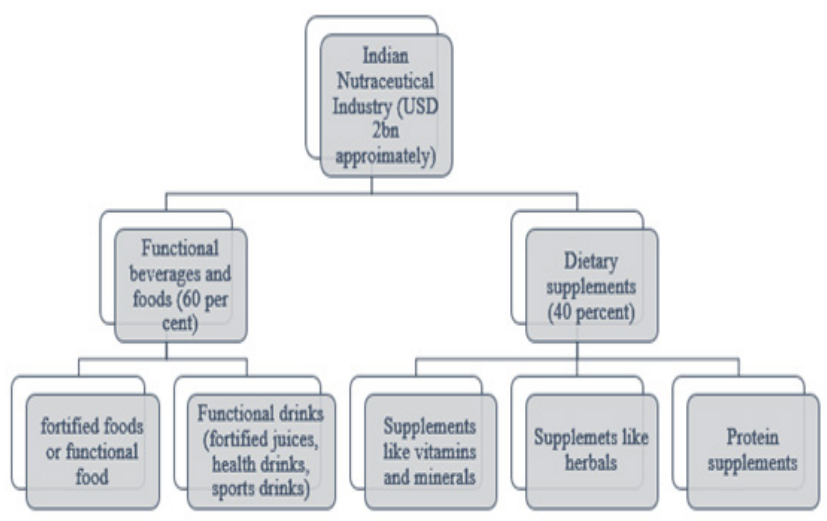

Figure 1: Indian Nutraceutical Market. ${ }^{1}$

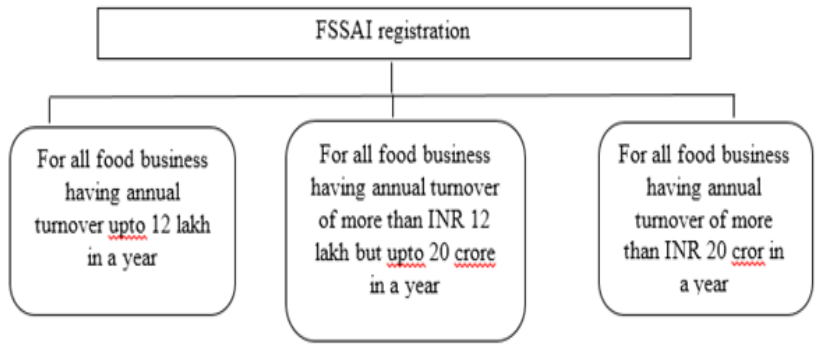

Figure 2: FSSAI registration fall under any one of the below three categories: a) Central License b) State License and c) Basic Registration. ${ }^{2}$

\begin{tabular}{|c|c|}
\hline 1 & Products pertaining to diary \\
\hline 2 & Fat emulsion; fats; oils \\
\hline 3 & Palatable ice \\
\hline 4 & Fruits; and vegetables \\
\hline 5 & Confectionery \\
\hline 6 & Cereals products and cereals \\
\hline 7 & Products pertaining to Bakery \\
\hline 8 & Products of Meat \\
\hline 9 & Products of Fish \\
\hline 10 & Eggs \\
\hline 11 & Sweeteners like honey \\
\hline 12 & Salads, Spices, Salt and Sauce \\
\hline 13 & $\begin{array}{l}\text { Type of foodstuffs necessary for nutritional } \\
\text { requirement }\end{array}$ \\
\hline 14 & Beverages \\
\hline 15 & Saviours like - "ready to eat" \\
\hline 16 & Foods that are prepared like - composite food dishes \\
\hline 17 & $\begin{array}{l}\text { Product that are not covered under the categories of } \\
\qquad 1-16\end{array}$ \\
\hline 99 & $\begin{array}{l}\text { Added substances to food which are 'not intended for } \\
\text { immediate food intake' }\end{array}$ \\
\hline
\end{tabular}




\section{Steps for Obtaining FSSAI basic Registration ${ }^{3}$}

- Registration for FSSAI is obtained by sending a request to the Food and Safety Department under Form A.

- The applications are approved or Department will deny it within the seven days from the date the application and must be conveyed in writing to applicant. When the application is approved, then Department must issue a certificate of registration with the registration number along with the applicant's photo.

- At the business place, the registration certificate will be placed during business hours.

\section{Licensing ${ }^{3}$}

Every FBO within country must be authorized under India's FSSAI. The process and criteria for licensing and registration are governed by the Food Safety and Standards (Licensing and Registration of Food Business) Regulation, 2011.

An online system namely Food License and Registration System is introduced by FSSAI to make it easier for FBOs in India for applying for license or for the registration certificates and to support they monitor their submissions throughout the processing. Figure 3 represents Licensing process for FBO in India.

\section{Requirements for Eligibility}

1. Yearly Revenue Turnover should be twelve lakhs to twenty crores for a food company. Including units for milling of grain; cereals; and pulses

2. For the Central License- Yearly Revenue Turnover should be more than twenty crores for a food company. And functioning in two or more States.

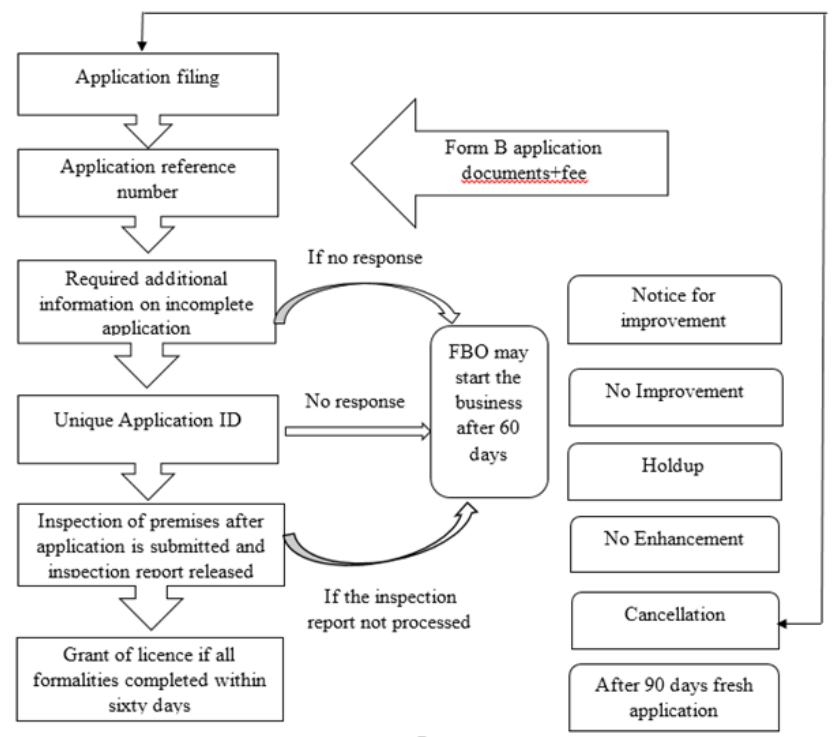

Figure 3: Licensing Process for FBO in India. ${ }^{3}$

\section{Registration ${ }^{4}$}

Registration is intended for small-scale food producers like small-scale traders, dealers, vendors or provisional stall holders or cottage industries with annual turnover of up to 12 lakes. All food businesses with profits in excess of this cap must take a license. Figure 4 represents Registration process for FBO in India and Table 2 shows Licensing and registration forms and schedules for food business

\section{Food Licensing and Registration System (FLRS) ${ }^{5}$}

FLRS (Food Licensing and Registration System) is an online system introduced by FSSAI to facilitate the issuance of a License / Registration Certificate by $\mathrm{FBO}$ in India and to monitor their applications during processing. All Central Licenses are issued

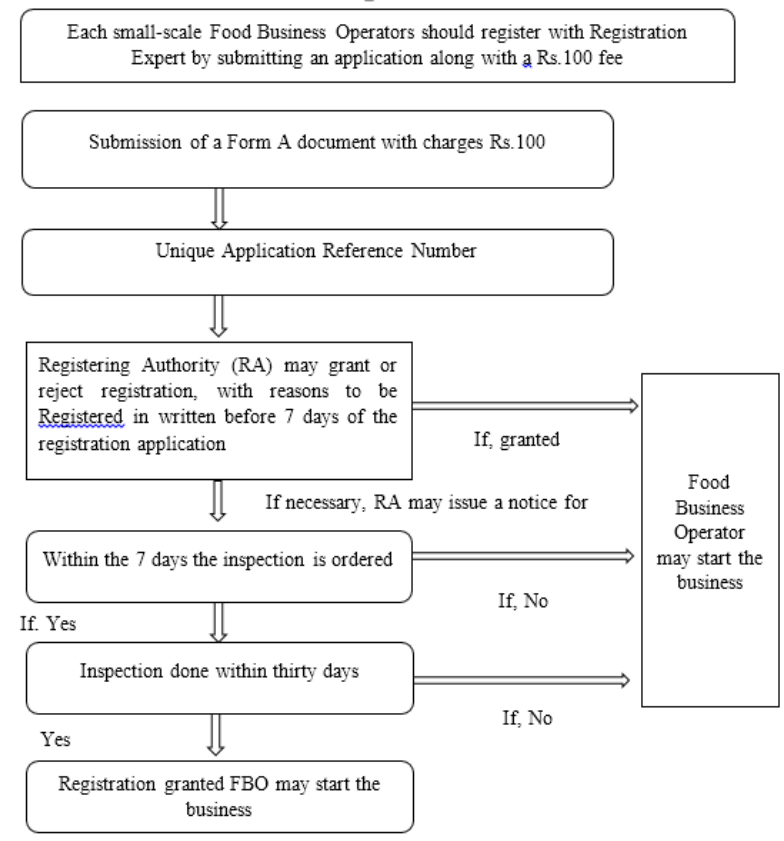

Figure 4: Registration process for FBO in India. ${ }^{4}$

\section{Table 2: Licensing and registration forms and} schedules for food business. ${ }^{4}$

\begin{tabular}{|c|c|}
\hline FORM 'A' & $\begin{array}{r}\text { Request for the Registration / renewal of Food } \\
\text { Safety Standard act 2006 }\end{array}$ \\
\hline FORM 'B' & Submission or renewal of license \\
\hline FORM 'C' & Licensing format \\
\hline FORM 'D' & Annual return other than for milk products \\
\hline FORM 'E' & Form of assurance \\
\hline SCHEDULE 1 & $\begin{array}{r}\text { List of Food businesses for which the central } \\
\text { licensing authority is responsible }\end{array}$ \\
\hline SCHEDULE 2 & $\begin{array}{r}\text { License registration/ license renewal fee per } \\
\text { annum }\end{array}$ \\
\hline SCHEDULE 3 & $\begin{array}{r}\text { Good hygiene and the sanitary standards that } \\
\text { Food Business Operators need to obey }\end{array}$ \\
\hline
\end{tabular}


online pan India through FLRS system with minimum documentation. The system has reduced the need for physical interaction between applicants and Licensing Authorities. License number or registration number of 14 digits will be issued to all food business suppliers, retailers, restaurants which must be printed on food labels and presented at the prominent location.

\section{Eligibility Criteria for License/Registration ${ }^{5}$}

\section{Registration}

1. Petty Manufacturers, dealer seller, hawker, itinerant seller or temporary holder of stalls.

2. Small food companies with yearly revenue turnover of $\geq$ twelve lakhs.

3. Food processing capacity $\geq 100 \mathrm{~kg} / \operatorname{ltr}$ per day.

4. A capacity of up-to 500 litres of milk should be handled and stored

5. Slaughtering Capacity per day - two big or ten small animals; fifty birds of poultry or lesser.

\section{Central License}

1. Liquid milk of capacity $\geq 50000$ litres per day or $\geq 2$ MT (Milli ton) per year for the dairy firms selling it.

2. A capacity of $\geq 2$ MT / day should be made for vegetable oil processing or for production units

3. $\geq 2 \mathrm{MT} /$ day should be established for all processing units of food excluding grains; cereals; and milling units of pulses

4. All importers importing foodstuffs for industrial use including food products and additives.

5. All food business operators manufacture / process / import any licensed food for which FSSAI has provided NOC.

6. Licensed / FBO headquarters located in two or more States.

7. Nutrition catering facilities in Central Government institutions and divisions such as railway, airlines, sea port, defence etc.

8. Hotels with a 5-star accredited and beyond and Table 3 describes documents to be included in New Application for a Central Licensing Authority.

\section{State License}

1. Every FBOs apart from those qualifying for a Central License / Registration.

2. Every units of milling wheat, cereals and pulses.

\section{FSSAI Main Nutraceutical Production Requirements in India ${ }^{8}$}

Nutraceuticals define "the sources of food applicable for obtaining a product with additional benefits to health other than the usual nutritional value present in foods". There was, however, a thin line between defining nutraceuticals as "food" or "drug." Since there is now a separate regulation for nutraceuticals, FBOs manufacturing nutraceuticals will need to follow the new FSSAI standards. FSSAI has standardized nutraceuticals so they may contain only for any of the constituents as detailed in the Schedule I to Schedule VIII. The sources of food applicable for obtaining a product with additional benefits to health other than the usual nutritional value present in foods

- Vitamin and mineral are included in Schedule I

- All amino acid and the other nutrient are set out in Schedule II

- Plant or ingredients of botanical in Schedule IV

- Schedule VI contains nutraceutical ingredients

- Schedule VII has strains (live micro-organisms) and probiotics

- And list of prebiotics in the Schedule VIII

\section{Labelling of Nutraceuticals ${ }^{8}$}

FSSAI has set strict labelling criteria and notes that the packaging, presentation and advertisement must not imply that the nutraceutical has any property that prevents any human disease from being treated or healed and that it cannot make any reference to such properties.

- the word "NUTRACEUTICAL";

- the common name of a nutraceutical

- Declares the quantity of each nutraceutical component of product that has a nutritional or physiological impact in it.

- Where appropriate, the nutrient quantity shall be expressed in appropriate proportion terms recommended daily allowances as defined by the Indian Council of Medical Research even if the nutrient is present along with the nutraceutical supplement and carry an advisory notice 'not to exceed the indicated recommended daily usage'

- Recommended warnings on labels must have

- "Recommended usage"

- "NOT FOR MEDICINAL USE" written prominently

- Any danger which may occur with additional consumption

- Contraindications and product-drug reactions, precautions to be taken when eating or in case of any side effects reported.

The labelling must also bear the declaration that the products should require to be stored out of reach of the children. 
Table 3: Documents to be included in New Application for a Central Licensing Authority. ${ }^{6,7}$

Documents to include for New License Application

\section{Central Licensing Authority}

1. Form-B Filled out along with signature

2. Blueprint for processing unit; plan of layout providing the measurements in meters / square metres, and the area allocation for service

3. List of Directors; Partners; Proprietor; Executive Members with full address and contact information

4. Names and number of equipment and machinery along with number, capability installed and power used

5. Evidence for address and Photo I.D should be given by Proprietor Government authority

6. List of food categories that desire to manufacture

7. Letter of authority with name and address of person responsible

8. Report analysis

9. ownership premises proof

10. Self-declaration for the proprietorships.

11. Copy of certificates received under Coop Act-1861/Multi

State Coop Act-2002

12. NOC and copy of Manufacturer's License

13. A plan or certification for the management of the food safety process

14. Source of milk or milk procurement program including where milk collection centres are located etc.

15. Meat processing projects and processing plants should describe the raw material source

16. Residues of pesticides Water study for units supplying packaged drinking water

17. Plan for recall

18. Municipal or local authorities NOCs

19. Certification from the ministry of commerce

20. Supporting documentary evidence for turnaround

21. NOC / PA document issued by FSSAI (should be Merge it into one document in case of multiple documents and then uploaded)

22. Code issued from government

23. Form IX: Business appointment of persons, along with board resolution.

24. Certificate given by tourism ministry (HRACC). (To Hotel

Only)

25. For Transporters-Supporting documentary evidence of

turnover or number of vehicles self-declaration (Mandatory for

Transporter Only)

26. Declaration forms

\section{Form-B Filled out along with signature}

2. Blueprint for processing unit; plan of layout providing the measurements in meters / square metres, and the area allocation for service

3. List of Directors; Partners; Proprietor; Executive Members with full address and contact information

4. Names and number of equipment and machinery along with number, capability installed and power used

Evidence for address and Photo I.D should be given by Proprietor

5. Government authority

6. List of food categories that desire to manufacture

7. Letter of authority with name and address of person responsible

8. Report analysis

9. ownership premises proof

10. Self-declaration for the proprietorships.

11. Copy of certificates received under Coop Act-1861/Multi State Coop Act-2002

12. NOC and copy of Manufacturer's License

13. A plan or certification for the management of the food safety process

14. Source of milk or milk procurement program including where milk collection centres are located etc.

15. Meat processing projects and processing plants should describe the raw material source

16. Residues of pesticides Water study for units supplying packaged drinking water

17. Plan for recall

18. Form IX: Business appointment of persons, along with board resolution.

19. Certificate given by tourism ministry (HRACC). (To Hotel Only) 20. For Transporters-Supporting documentary evidence of turnover or number of vehicles self-declaration (Mandatory for Transporter Only)

21. Declaration forms

\section{Nutritional information ${ }^{9}$}

a. "Health claims" The nutrient physiological function in the growth; development; and normal functions of the body, certain functional entitlements relating to the particular beneficial impact of food intake or its constituents on the normal functions or biological activities of body in the sense of the total diet and these claims gives to a positive contribution for health or function enhancement or health related conditions;

b. "Nutrition claims" Means any description that indicates an ideal nutritional characteristic are there for food that are unrestricted to the energy value, however these include proteins; fat carbohydrates; vitamins and minerals;

c. "Risk reduction" Reducing risk in the form of health claims involves substantially changing a major risk factor for the disease or disorder associated with the safety.

\section{United States ${ }^{10,11}$}

Food and Drug Administrations (FDA) regulatory authority has a very wide scope. The functions of the FDA are strongly related to those of various other government bodies. The commonly accepted food 
products coming under the regulatory jurisdiction of the FDA is listed below.

- Dietary supplements

- Water in bottle

- Formulations for Infant

- Additives related to food

- Other food items like egg, poultry and meat products (even though U.S Department of Agriculture (USDA) regulates some products of it).

Food business subjected to regulation of FDA ${ }^{12}$

The FDA regulates all food and food additives imported or sold for interstate trade, except egg, poultry and meat products which are under USDA regulation.

The Center for Food Safety and Applied Nutrition (CFAN) in coordination with FDA field offices works together to make sure that the supply of national food items (other than those controlled by USDA) is safe, healthy, wholesome and accurately labelled. This also ensures the proper labelling and safe use of cosmetic products.

\section{Food business NOT regulated under FDA are}

- State and local government regulated food retailing establishments (e.g. restaurants, grocery stores food trucks and cafeteria)

- Markets of farmers.

\section{Starting of a Food Business}

Apart from the requirements of the FDA, business of food will be also exposed to certain federal, state and local regulations. This can differ depending on the product and the facility operation style. Relevant products and services should be discussed with the FDA District Office and the external entities that have authority to run a food business.

\section{Registration of Food Facility ${ }^{13}$}

Section 415 of FD\&C Act was amended by FDA Food Safety Modernization Act (FSMA) released on 4 January 2011, to enable facilities involved in the food manufacturing, processing, packing and storing for use in US to submit extra details of registration to FDA and food facilities needed to register with the FDA in order to re-register with the FDA every next year and the FDA is given the right to cancel food facility registration in some situations.

In particular, if FDA finds that the food products from a registered food facility is likely to cause serious adverse health issues or harm human or animal, a suspension order is passed for the facility that:
- Can cause, created or was liable for a similar reasonable possibility.

- This kind of reasonable possibility and have packed, received and stored these foods.

\section{Dietary Supplement ${ }^{14}$}

All finished dietary supplements and ingredients of these supplements are regulated by FDA. Various other regulations than any of those relating to 'conventional' foods and medicines are followed for the dietary supplement regulation.

A dietary supplement as per the Congress in the Dietary Supplement Health and Education can be defined as a product which

- Can add on to a diet

- Consists of one or more DI's and its constituents (like vitamins, minerals, herbal or botanical items, amino acids).

- Shall be taken as a pill, capsule, bottle, or liquid through mouth is labelled as a dietary supplement on the front panel

The Dietary Supplements Health and Education Act (DSHEA), 1994 regulates dietary supplements. Moreover, it is not mandatory for both manufacturers and distributors of dietary supplements to receive FDA approval before they market dietary supplements. The company is responsible to ensuring that the produced or distributed products of it are absolutely safe until that company sells a dietary supplement; any statements regarding the products are not really false or misleading and the also these products should ensure compliance with the FFD\&C Act FDA in all respects.

\section{Regulation of supplement ${ }^{15}$}

1. The "dietary supplement" term or a term replacing the product DI description for the term "dietary" should be used to define a dietary supplement as per federal law.

2. Federal law does not mandate that FDA must provide proven safe dietary supplements.

3. For the most claims made in dietary supplement labelling, as per the law there is no need to give evidence to FDA by the manufacturer or sales person.

4. Typically, the role of FDA with a dietary supplement product starts once the product marketed. It is typically the initial opportunity for the agency to take action towards a substance which poses a serious or excessive disease or injury risks, or when it is adulterated or misbranded.

5. The Federal Trade Commission is authorized to allow dietary supplement advertisements, even those broadcasts on radio and television. 
6. Once a dietary supplement is marketed, several responsibilities are there for FDA in ensuring safety. Mandatory adverse event reporting by the dietary supplement firms as well as consumer and healthcare voluntary reporting of adverse event monitoring are included in this.

7. Dietary supplement companies are expected to disclose to the FDA any significant adverse effects that patients or health care practitioners report to them.

8. Manufacturers of dietary supplements do not require approval from the agency prior to the product production or sale.

9. Dietary supplement product marketing for specific disease treatment or cure, or alleviating the disease symptoms, is not legal.

10. FDA's Claim monitoring by FDA in dietary supplement labelling is limited.

\section{cGMP Final Rule for Dietary Supplement ${ }^{16}$}

1. US FDA published the final rule setting down dietary supplement regulations $f$ on the requirement of current good manufacturing practices (cGMP).

2. The proposed final rule on CGMP would allow strict regulations for dietary supplements to be in place so that they are manufactured efficiently and meet quality requirements.

3. The cGMPs extend to both domestic and international firms manufacturing, packaging, labelling, or maintaining dietary supplements, as well as those engaged in testing, quality assurance, packaging and labelling operations and marketing these in the US.

4. The rule lays down cGMPs for wide usage in industry that are essential to ensure dietary supplements clear identification, purity, quality and composition.

5. The specifications include provisions on:

- Physical plant design and construction which facilitates maintenance

- Cleanliness

- Adequate manufacturing processes

- Procedures for the quality control

- Testing of finished or incoming products as well as in process materials

- Handling complaints by users

- Record maintenance

The law has a scheduled three-year phase-in for small businesses in order to minimize potential damage to dietary supplements provided by small companies. For large corporations, the final cGMPs were effective in June 2008. Companies with less than 500 employees are in compliance with the rules until June 2009 and firms with less than 20 employees are in compliance by June 2010 .

\section{Label claims for dietary supplements ${ }^{17}$}

There are three claim types, namely health claim, nutrient claim and structure/ functional claim as specified by statute and/or FDA regulations, that may be applied to food and dietary supplement labels.

- Health claims

By definition two important parts a "health claim" contains: (i) a substance (if it is a food, component of food or food ingredient) and (ii) a condition that is connected to a disease or health. If the statement is missing any of these components it will not fulfil regulatory concept of health claim.

\section{- Nutrient content claim}

The Nutrition Labelling and Education Act of 1990 (NLEA), if it is FDA approved and is in compliance with the regulations of FDA authorization, permits label claim usage which distinguish food nutrient level (i.e. nutrient content claims). Nutrient level arguments define the product nutrient level, with terms like free, high and low, or with terms like more, reduced and lite, comparing the food nutrient level with that of other foods.

- Structure/ function entitlements and related dietary supplement claims:

Structure / functions entitlements may describe nutrient or DI role that is considered to influence the human body's normal structure or function, for example, "calcium is responsible for building strong bones". These also describing the function of a nutrient or DI in keeping certain structure or function, such as "fiber maintains bowel regularity".

\section{Labelling requirement for dietary supplement ${ }^{18}$}

Information that is specified on the dietary supplement label as per FDA requirement includes the following.

$>$ General information

- Product name (containing the term "supplement" or a product supplement statement).

- Content net quantity

- Manufacturer, packer or distributor name and business place

- Usage direction

- Facts panel of supplements

Size of serving, DI list, quantity per serving size (by weight), daily value percentage (\% DV) when specified.

When the ingredient of diet is a botanical product, it is specified by its scientific name or the common 
name or usual name in the Herbs of Commerce guide (1992 edition) along with used plant component name.

When the DI is a proprietary blend, the total blend weight and blend components should be according to weight predominance.

\section{Other ingredients}

Non-nutritional ingredients like filler, artificial colours, sweeteners, flavours or binders; indicated by descending order their weight and by common name or proprietary blend.

Usually supplement label includes a cautionary statement; however, any absence of a cautionary statement does not indicate that the product is not associated with any adverse effects.

\section{New dietary ingredient (NDI) ${ }^{19}$}

As specified in the FD\&C Act, any of the below mentioned is a "dietary ingredient":

(i) A Vitamin

(ii) A mineral

(iii) An herb or other botanical

(iv) An amino acid

(v) A human consuming dietary product to complement the diet by increasing the total dietary intake. (vi) A concentrate, metabolite, constituent, extract or combination of any mentioned ingredient in (i), (ii), (iii), (iv) or (v).

If a DI is not in US market before 15 October 1994 it is regarded as NDI. Therefore, a product must be a DI to become an NDI. Figure 5 represents New Dietary Ingredients notification and Table 4 denotes the Submission of NDI notification and Information to be included during submission. Nutraceutical regulations in India and US are compared in Table 5.

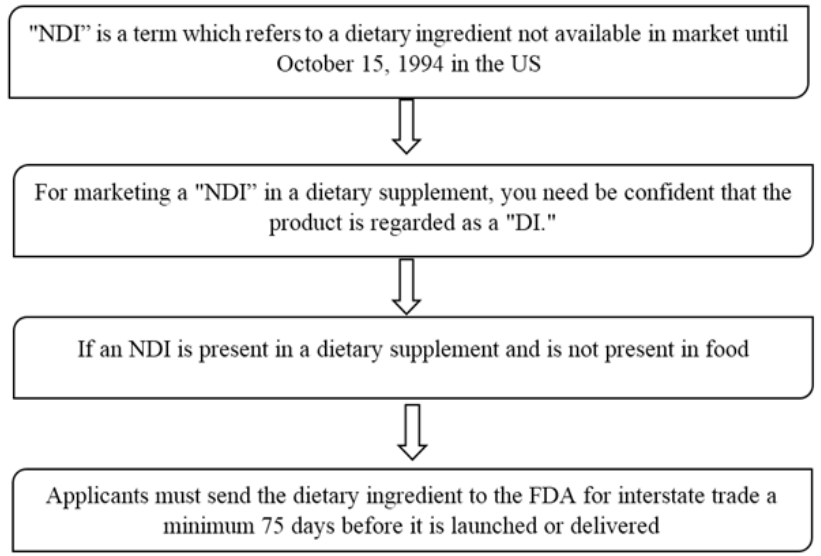

Figure 5: New Dietary Ingredients notification. ${ }^{19}$

\section{Table 4: Submission of NDI notification and Information to be included during submission. ${ }^{20}$}

\section{Information to be included in notification}

- Name and complete address.

- Name of new dietary ingredient. If herbal or botanical new dietary ingredient is used, the Latin binomial name (include the author) must be included.

- An overview of the dietary supplements or supplements containing the NDI, including the following:

- $\quad$ Product NDI level

- $\quad$ recommended product usage condition or specified in the labelling

- usage history or certain safety evidence

- The signature of a responsible person for the notification content whom you appoint and can be contacted if we have any queries.

\section{Notification Submission}

- A premarket notification should be submitted if you are a:

- To market a NDI as per Manufacturer plan.

- Manufacturer planning to sell a dietary supplement containing a NDI

- Distributor planning to market a NDI

- Distributor planning to market a dietary supplement containing a NDI.

Table 5: Comparison of nutraceutical regulations in India and US. ${ }^{21}$

\begin{tabular}{|c|c|c|}
\hline Parameter & India & USA \\
\hline Regulation & FSSAI regulates nutraceuticals. & DSHEA regulates dietary supplements \\
\hline Licensing and registration & FSSAI & US FDA \\
\hline Definition & $\begin{array}{l}\text { Nutraceuticals are defined by FSSAI as "food } \\
\text { for special dietary use". }\end{array}$ & $\begin{array}{l}\text { Under DSHEA, FDA defines nutraceuticals as } \\
\text { "dietary supplement". }\end{array}$ \\
\hline $\begin{array}{l}\text { Regulatory authority/act for } \\
\text { nutraceutical registration }\end{array}$ & FSSAI & DSHEA \\
\hline $\begin{array}{l}\text { Regulatory Registration } \\
\text { requirements }\end{array}$ & $\begin{array}{l}\begin{array}{c}\text { Evaluation of product, licenses, health and label } \\
\text { claims }\end{array}\end{array}$ & $\begin{array}{l}\text { Product licence, safety and efficacy evidence, } \\
\text { labelling, health claims, clinical trials and adverse } \\
\text { reaction reporting, GMP }\end{array}$ \\
\hline Registration forms & Form $\mathrm{A}, \mathrm{B}$ and $\mathrm{C}$ & Form 3537 \\
\hline
\end{tabular}




\section{CONCLUSION}

In US nutraceuticals are classified under dietary supplements and do not even need notification for existing products to help manufacturers spend less time and cost-effective clearance, but this poses a major risk to customers without sufficient protection. New products need notice of novel dietary ingredients. Therefore, even well-established product that make them safe to consume must be framed for minimum notification standards.

In India FSSAI controls nutraceuticals in India and they are listed under the food. These products are governed and specified in compliance with FSSAI Act that requires notification. The notification is less timeconsuming and cost-effective which is beneficial to business and customers alike. The 2010 FSSAI legislation and 2011 Regulation on imports make the system more stringent. Separate licenses are required for different manufacturers, importers and marketing according to the type of company in which they are associated.

While the enforcement of food safety acts poses several obstacles, Regulatory Agency is moving forward with a resolution to provide specific and consistent legislation for dietary, food additives and nutraceuticals. Overall, the prospects for nutraceuticals are increasing scientifically and identifying nutritional components for each of the potential diseases; more natural treatments are also requested by customers. Knowing this company should use this approach as a way to introduce services to the people who desperately need them.

\section{ACKNOWLEDGEMENT}

Authors thank JSS Academy of Higher Education and Research and JSS College of Pharmacy, Mysuru for providing necessary facilities to carry out this work.

\section{CONFLICT OF INTEREST}

The authors express "No conflict of interest" for publication of this manuscript.

\section{ABBREVIATIONS}

cGMP: Current Good Manufacturing Practices; DI: Dietary Ingredient; DSHEA: Dietary Supplements Health and Education Act; DV: Daily Value; FBO: Food Business Operator; FDA: Food and Drug Administration; FD and C: Food, Drug and Cosmetics Act; FLRS: Food Licensing and Registration System; FSMA: Food Safety Modernization Act; FSSAI: Food Safety Regulatory Authority of India; MT: Milli Ton;
NDI: New Dietary Ingredient; NLEA: Nutrition Labelling and Education Act of 1990; NOC: No Objection Certificate; US: United States; USDA: U.S Department of Agriculture.

\section{REFERENCES}

1. Food Categorization Code n.d. https://foodlicensing.fssai.gov.in/PDF/Food_ Categorization_Code.pdf (accessed February 17, 2020).

2. Food Registration Under FSSAI n.d. https://taxguru.in/corporate-law/foodregistration-fssai.html (accessed February 17, 2020).

3. FSSAI n.d. https://fssai.gov.in/cms/licensing.php (accessed February 17, 2020).

4. FSSAI n.d. https://fssai.gov.in/cms/registration.php (accessed February 17, 2020).

5. Food Regulatory Portal - One Nation, One Food Law n.d. https:// foodregulatory.fssai.gov.in/flrs (accessed February 17, 2020).

6. FSSAI Licensing and Registration System n.d. https://foodlicensing.fssai.gov. in/central document_list.html\#about-tab (accessed February 17, 2020).

7. FSSAI Licensing and Registration System n.d. https://foodlicensing.fssai.gov. in/state_document_list.html\#about-tab (accessed February 17, 2020).

8. FSSAI Key Requirements for Manufacturing Nutraceuticals in India - Food Safety Helpline n.d. https://foodsafetyhelpline.com/fssai-key-requirementsmanufacturing-nutraceuticals-india/ (accessed February 17, 2020).

9. Food Safety and Standards (Packaging and Labelling) Regulations, 2011 n.d. https://fssai.gov.in/upload/uploadfiles/files/Packaging_Labelling_ Regulations.pdf (accessed February 17, 2020).

10. What does FDA regulate? | FDA n.d. https://www.fda.gov/about-fda/fdabasics/what-does-fda-regulate (accessed February 17, 2020).

11. FD\&C Act Chapter IV: Food | FDA n.d. https://www.fda.gov/regulatoryinformation/federal-food-drug-and-cosmetic-act-fdc-act/fdc-act-chapter-ivfood (accessed February 17, 2020).

12. How to Start a Food Business | FDA n.d. https://www.fda.gov/food/foodindustry/how-start-food-business (accessed February 17, 2020).

13. Registration of Food Facilities and Other Submissions | FDA n.d. https://www. fda.gov/food/guidance-regulation-food-and-dietary-supplements/registrationfood-facilities-and-other-submissions (accessed February 17, 2020).

14. Dietary Supplements | FDA n.d. https://www.fda.gov/food/dietarysupplements (accessed February 17, 2020).

15. FDA 101: Dietary Supplements | FDA n.d. https://www.fda.gov/consumers/ consumer-updates/fda-101-dietary-supplements (accessed February 17, 2020).

16. Current Good Manufacturing Practices (cGMPs) for Dietary Supplements FDA n.d. https://www.fda.gov/food/current-good-manufacturing-practicescgmps-food-and-dietary-supplements/current-good-manufacturing-practicescgmps-dietary-supplements (accessed February 17, 2020).

17. Label Claims for Conventional Foods and Dietary Supplements | FDA n.d. https://www.fda.gov/food/food-labeling-nutrition/label-claims-conventionalfoods-and-dietary-supplements (accessed February 17, 2020).

18. Background Information: Dietary Supplements - Health Professional Fact Sheet n.d. https://ods.od.nih.gov/factsheets/DietarySupplementsHealthProfessional/ (accessed February 17, 2020).

19. New Dietary Ingredients in Dietary Supplements - Background for Industry | FDA n.d. https://www.fda.gov/food/new-dietary-ingredients-ndi-notificationprocess/new-dietary-ingredients-dietary-supplements-background-industry (accessed February 17, 2020).

20. Verma B, Popli H, Bhawna Verma C. Regulations of nutraceuticals in India and us. $~ 811 \sim$ The Pharma Innovation Journal 2018;7:811-6 http://www. thepharmajournal.com/archives/2018/vol7issue7/PartM/7-7-91-540.pdf (accessed February 17, 2020).

21. Jain Pooja N, Rathod Meera H, Vineet Jain C, S. M. Vijayendraswamy Current Regulatory requirements for Registration of Nutraceuticals in India and USA - Google Search n.d. http://ijdra.com/index.php/journal/article/ download/232/131 (accessed February 18, 2020). 


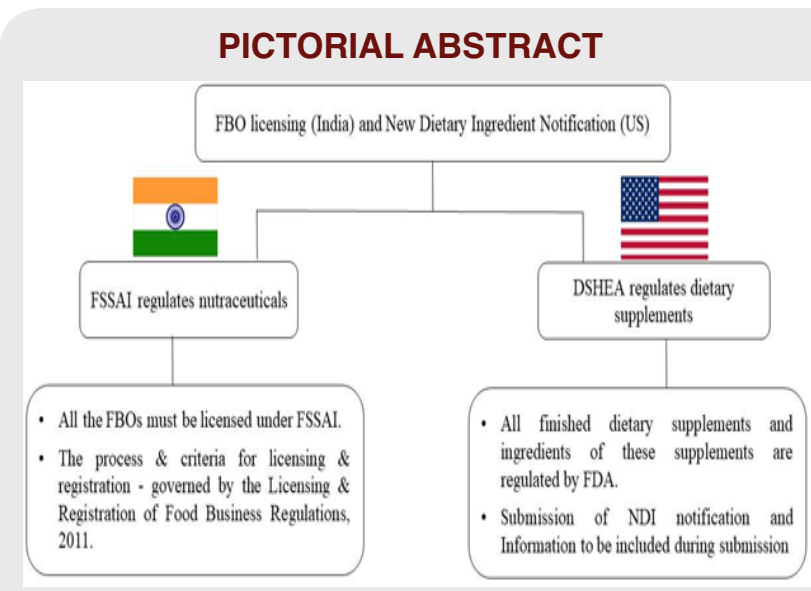

\section{SUMMARY}

- The nutraceuticals are termed as "Foods for Special Dietary Uses" in India and in USA it is described as "Dietary supplements"

- Demand for nutraceuticals is growing day by day, it has been noted that around $60-70 \%$ of dietary supplements marketed in India are false, counterfeit, unsecured and unauthorized.

- FSSAI has defined regulatory guidelines for approval of nutraceuticals in the Indian market.

- FSSAI criteria for nutraceuticals [licensing, registration and regulatory requirements] in India is compared to US dietary supplements / dietary ingredients [registration, regulations, cGMP, label claims and labelling]

- In US, nutraceuticals do not need notification for existing products; whereas nutraceuticals listed as Food in India need notification.

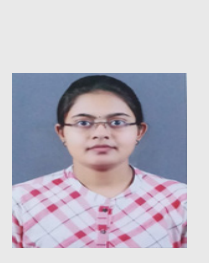

\begin{abstract}
About Authors
Ms. Nandhini has done her B.Pharm, M.Pharm (Pharmaceutical Regulatory affairs) and PG Diploma in Pharmaceutical Quality Assurance from JSS College of Pharmacy, Mysuru, Karnataka. She has worked extensively on the Nutraceutical regulations in different countries. She is presently working as Trainee-Regulatory Document and Submission Support at Merck Healthcare KGaA, Bengaluru.
\end{abstract}

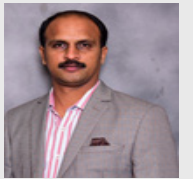

Dr. M. P Venkatesh is Assistant Professor at JSS College of Phamacy, Mysuru. He is the Coordinator of M.Pharm - Pharmaceutical Regulatory Affairs program and PG Diploma in Drug Regulatory Affairs. He has over 15 years of teaching and research experience. He has 132 publications in international and national journals mainly in regulatory sciences and novel drug delivery systems.

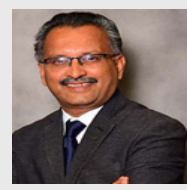

Dr. T. M. Pramod Kumar is Professor and Principal of JSS College of Pharmacy, Mysuru. In his career of over 27 years, he has guided over 70 M.Pharm, $13 \mathrm{Ph}$. Ds and 184 publications in reputed journals. He has contributed in various National platforms as members representing the institution. His expertise lies in pharmaceutical formulation development, regulatory sciences and 3D printing.

Cite this article: Nandhini B, Venkatesh MP, Kumar TMP. Overview of FBO licensing in the India and New Dietary Ingredient Notification in the US. Indian J of Pharmaceutical Education and Research. 2021;55(2):336-45. 